\title{
Clinicians, researchers and community activism: lessons for mental health services from another field of medicine - HIV/AIDS
}

\author{
Robert Miller ${ }^{1}$
}

The Psychiatrist (2013), 37, 81-84, doi: 10.1192/pb.bp.111.037978

${ }^{1}$ University of Otago, Wellington, New Zealand

Correspondence to Robert Miller (robert.miller@anatomy.otago.ac.nz)

First received 27 Nov 2011, final revision 14 Jul 2012, accepted

21 Aug 2012

\begin{abstract}
Summary Consumer participation in mental health services has grown in recent years. Preceding this, a very productive collaboration in another area - the emerging crisis of HIV/AIDS - built a coalition of service users, researchers and clinicians which had a decisive impact on research and saved many lives. There is much to learn from this for the mental health field, where, at present, partnership between service users, caregivers, researchers and clinicians is not such a productive force. This editorial outlines the respective histories in these two areas and the lessons to be learnt for consumer involvement in the mental health field.
\end{abstract}

Declaration of interest None.

\begin{abstract}
The consumer movement in the health industries has grown very rapidly in the past 20 years and is now a major force in most medical specialties and in many countries. ${ }^{1}$ This movement has been propelled from several quarters. One area (arguably the first to make a major impact) in which the alliance between consumers, researchers and clinicians has made particularly notable achievements is the field of HIV/AIDS. ${ }^{2}$ In Britain, the current strong alliance was forged in the 1980s and early 1990s, in advance of consumer movements in other areas of medicine (including mental health). A key figure at this time was Nick Partridge (now Sir Nick Partridge, CEO of the Terrence Higgins Trust, www.tht.org.uk). He has used his experience more recently in organisations concerned with community involvement in health services and health research generally, not just in the area of his initial commitment (these are INVOLVE, www. invo.org.uk, and the James Lind Alliance, www.lindalliance. org). This editorial summarises the conversation I had with Nick Partridge, and the conclusions I draw of relevance in the mental health area. The field of HIV/AIDS has a number of similarities to the mental health area, but also significant differences, which makes the comparison interesting.
\end{abstract}

\section{Similarities between HIV/AIDS and mental health}

In both areas there has been a culture of denial. Vicious circles of fear and ignorance have created barriers hindering the mounting of effective health programmes. ${ }^{3,4}$ In the mental health area readers of this editorial will need no further elaboration of this point. In the HIV/AIDS area, there have been powerful taboos preventing open discussion of topics of sexually transmitted diseases, homosexuality, and sexuality itself.
Both specialties have tended to be viewed as 'Cinderella areas' among medical specialties. ${ }^{5,6}$

Both psychiatry and HIV/AIDS have tended to be subjected to unhelpful and sometimes scurrilous and sensational reporting in the print media., ${ }^{7,8}$ They have attracted their share of activists who use media outlets with considerable skill to promote agendas which are either simplistic or manifestly incorrect in terms of scientific evidence. $^{9,10}$

Further, in both specialties it has been necessary for community activists to break through resistance of senior clinicians and researchers with respect to working with community spokespersons sitting on the same committees. Nevertheless, persistence has paid off and it is now recognised that fresh viewpoints from the community may highlight weaknesses in current research or practice. In AIDS, this has included areas of research that were going nowhere, or the inability of experts in one subspecialty to integrate valuable expertise from other fields into their thinking (N. Partridge, personal communication, 2011). ${ }^{2}$

\section{Differences between HIV/AIDS and mental health}

To begin with, mental health issues only sometimes become matters of life and death, whereas HIV/AIDs, from 1980s up to the late 1990s, was such a matter and on a large scale. HIV/AIDS can be defined much more precisely in terms of medical science than is possible for most mental illnesses. Community activism related to HIV/AIDS therefore had sharp focus on research, and especially on decisive clinical trials, in the hope of finding a cure or at least an effective treatment in the short term. In mental health, disorders are more difficult to define and are conceptually more complex. Fundamental research from which effective treatments or 
cures might emerge inherently has a much slower tempo and therefore community activism is focused more on service delivery or the respective merits of established strategies of treatment or clinical approaches.

Psychiatry, both historically and today, has been riven by a deep philosophical division, between the 'somatikers' and the 'psychikers' in 19th-century Germany, ${ }^{11}$ and the equivalent today of biogenetic $v$. psychosocial approaches to causation and treatment. ${ }^{12}$ There have been such philosophical splits in the HIV/AIDS area too, for instance by those who deny the viral aetiology of $\mathrm{HIV}^{3}$ but this is now mainly confined to fringe groups and any divisions are by no means so old and deep-rooted as those within psychiatry. An interesting comparison can be made here with another possibly infectious disease, myalgic encephalomyelitis (ME or chronic fatigue syndrome). This has been variously regarded as a psychiatric disorder (perhaps a form of depression) or as a viral disorder. However, the passionate insistence of service users is that ME does have a biological basis, not a psychological one, an emphasis exactly the opposite of that which often generally prevails among mental health service users.

In psychiatry, but not in HIV/AIDS, practising doctors have had the power to commit patients involuntarily, and this inevitable power imbalance has made it more difficult for patients and doctors to work together. Admittedly, in many jurisdictions nowadays it is not psychiatrists who have that power, since initial reports by psychiatrists are subject to routine legal review. It also needs to be said that in today's world the occasions when these powers are needed involve a small minority of patients (mainly those with psychotic disorders) compared with a generation ago. Nevertheless, the memory of the past lingers on in the public mind.

Finally, HIV/AIDS is definitely an unmitigated illness, whereas for many mental illnesses there may be an inseparable mixture of definite, sometimes severe impairment in one area of psychological function and unusual, even outstanding talent in other areas.

\section{History of consumer activism for HIV/AIDS}

Several things combined in the HIV/AIDS area leading to a very fruitful collaboration of consumers, clinicians and researchers. The sexual liberation, which occurred in the 1960s and 1970s and which increased openness about sexual matters, set the scene for this and led to a vigorous political movement among gay communities, especially in the USA. Without these, the collaboration might not have developed. In the middle and late 1980s there was a widespread sense of urgency and apprehension, shared jointly among groups at risk, clinicians and researchers. ${ }^{2}$ No one knew how big the problem might become. Among consumers, a body of young, articulate and energetic activists emerged. These included Terrence Higgins, who later died from AIDS and who was one of the first in Britain to grasp the size of the problem it represented. These developments created an environment where researchers and clinicians in the neglected fields of sexually transmitted and infectious diseases realised they were at the forefront of a very important area, and had to join forces with activists in the general community in pushing through their research agenda. Nevertheless, big international AIDS conferences in the late 1980s and early 1990s saw some rather stormy scenes. A powerful consumer movement grew rapidly (especially the group formed in the USA, and spreading internationally, AIDS Coalition to Unleash Power - ACT UP). In Britain, there was tension between consumer groups and researchers at the Wellcome Trust and the Medical Research Council (MRC), and mass demonstrations outside the MRC headquarters in London (as well as in Bethesda, Maryland, outside the National Institutes of Health). ${ }^{13}$ Consumers played a decisive role in the politics and science at the big research meetings, by pointing out the irrelevance of a lot of research. In important ways, they shaped the course of subsequent research. The hardest group of professionals to bring on board were those who were excessively concerned about the rigour of research, wanting absolute proof before turning laboratory findings into clinical trials or clinical trials into routine treatment. This is perhaps an unfortunate consequence of the thalidomide disaster in the 1960s. However, in the early 1990s, and with the Terrence Higgins Trust taking a leading role, collaborative research was undertaken, with close collaboration between the Terrence Higgins Trust and researchers. It involved working together on trial design, recruitment and rapid dissemination of results. A major trial of azidothymidine (the Concorde trial) had disappointing results at first, which were widely reported. ${ }^{14}$ However, by 1996 highly effective combination therapy with antiretroviral drugs was found, ${ }^{15}$ and this has now reduced the death rate from HIV/AIDS by $70 \%$.

\section{History of service user activism for mental health}

The history of the emergence of the service user movement in mental health has been rather different, and has not yet achieved the coherence seen earlier in the AIDS field. ${ }^{16}$ This was due to a set of circumstances.

The early community pioneers in the mental health area, starting in the 1970s, were family members, not patients themselves, in bodies such as the National Schizophrenia Fellowship in the $\mathrm{UK}^{17}$ and similar organisations in New Zealand and Australia. Active involvement of service users came later, probably because it took some time for them to overcome their own fears, related to the prevailing climate of stigma and discrimination. When this happened, separate organisations tended to emerge for family members and for service users, naturally enough since there are genuine differences of interest between the two. There were antagonisms between these groups, and also between service users and psychiatrists; to a degree this is still the case. There is now some coming together of the different players in the field, and there is a body of vigorous, well-informed, articulate activists in the community able to challenge orthodoxy. However, there is far from a united front among various service user groups on the basic philosophical divisions, and there are few activists who can assimilate biogenetic and psychosocial models of mental disorder into a coherent viewpoint. There is no unanimity on the proper 
roles of biology-based treatments and psychotherapies of various sorts.

Psychiatrists in most countries have been slow to engage with community activists. Major international conferences dealing with fundamental aspects of psychiatric research have been remarkably slow (compared with AIDS conferences) in bringing patients on board. In my own experience, at international congresses on schizophrenia (International Congress on Schizophrenia Research, Winter Workshops on Schizophrenia) in the 10 years before 2008, the last time I took part, I remember no keynote speakers who had lived experience of the disorder. In all the committees which compiled DSM-III, DSM-IV and now DSM-5, I understand that only once has a genuine lay person been included (in the DSM-III committee for posttraumatic stress disorder). ${ }^{18}$ This (in my view) is partly because psychiatrists have been unwilling to recognise that their patients could be intelligent commentators on the issues involved, but also because service user organisations have often been poorly informed and poorly advised by those held up as their leaders or spokespersons. As a result, psychiatrists often dismiss service user organisations collectively as extremists. ${ }^{16}$ It has then been difficult for psychiatrists who do want to engage with community groups to recognise those activists within these groups who are well informed and fully aware of the complexity of mental disorders and their treatment.

There has never been quite the sense of urgency and apprehension in the mental health field as seen at the height of the HIV/AIDS emergency. However, some psychiatrists are now fearful that the metabolic syndrome associated with some modern antipsychotic drugs constitutes a 'time bomb' which may lead to a major epidemic within a few years' time, and feel that urgent response is needed now. ${ }^{19}$

Ingrained scepticism among some researchers may parallel that in the HIV/AIDS field (for instance, by those who demand absolute proof that early intervention improves long-term outcome before agreeing to implement early intervention programmes). ${ }^{20}$ Fundamental research on biological mechanisms of mental illness is, at present, unlikely to attract a high level of enthusiasm from service user groups, much as such research may be needed.

\section{Suggestions of ways to improve partnership between mental health services and service users}

Clinical trials of new medications for mental disorders and other innovative treatments may produce important advances; and clinical trials might be possible without involving major pharmaceutical companies, and at a faster pace than most drug development (as happened in the HIV area). However, this would depend on the formation of a solid coalition between service users and researchers, with shared perspective overriding philosophical splits of the past. Drawing on the history of the AIDS activist movement, a major step forward would be for those who have experience of major mental illness, and their family members, to be invited as independent participants in designing clinical trials for new therapies and in the evaluation of results. This might avoid setbacks in acceptance of effective therapies due to unhelpful publicity (as happened initially with azidothymidine for HIV-positive individuals) as well as distortion in reporting of results for commercial reasons.

Service users and caregivers should also be invited to participate in the processes leading to the formulation of systems of psychiatric diagnosis.

Another area where a coalition of clinicians, researchers, patients and family members might emerge (and often already has done) is in service delivery and related research. This might involve introducing a stronger research culture to clinical services, so that what is known to work well in the best services could be emulated more widely. Although research studies necessarily have a slower tempo in mental health than in HIV/AIDS, relatively rapid improvement may be expected from engagement of service users in policy development for mental health services (just as it is in service delivery, rather than decisive clinical trials, that there may be the most immediate impact).

Service users are the ones most aware of the subtleties of discriminatory use of language, including language used by clinicians. Much of this occurs at an implicit, or subconscious, level. Users may be able to offer thoughtful advice on how this can be avoided.

Finally, Nick Partridge's advice on strategy for community groups was: 'Use charm, but combine it with steely determination. Mobilise personal, political, social, commercial, and media forces - and gather momentum. Have an eye on the long term, but plan short term - flexibility is the key. Build up your allies . . . and keep going!'

\section{Acknowledgements}

I would like to thank Sir Nick Partridge, Tim Peto, Rob Kydd and Geoff Denham for inspiration and useful comments on drafts.

\section{About the author}

Robert Miller is a freelance researcher and honorary fellow, Department of Psychological Medicine, University of Otago, Wellington, New Zealand. He is a community representative on committees of the Royal Australian and New Zealand College of Psychiatrists.

\section{References}

1 Allsop J, Jones K, Baggott R. Health consumer groups in the UK: a new social movement? Sociol Health IIIn 2004; 26: 737-56.

2 Pripstein J. When science and passion meet: the impact of AIDS on research. CMAJ 1993; 148: 638-42.

3 Chigwedere $\mathrm{P}$, Essex M. AIDS denialism and public health practice. AIDS Behav 2010; 14: 237-47.

4 Hinshaw SP Cicchetti D Stigma and mental disorder: conceptions of illness, public attitudes, personal disclosure, and social policy. Dev Psychopathol 2000; 12: 555-98.

5 Hall LA. 'The Cinderella of medicine': sexually-transmitted diseases in Britain in the nineteenth and twentieth centuries. Genitourin Med 1993; 69: 314-9.

6 Van Os J, Neeleman J. Caring for mentally ill people. BMJ 1994; 309 1218-21.

7 Clement S, Foster N. Newspaper reporting on schizophrenia: a content analysis of five national newspapers at two time points. Schizophr Res 2008; 98: 178-83. 
8 Garnett G, Anderson R. AIDS, HIV and the Sunday Times (letter). Nature 1993; 366: 716

9 Science Guardian Awards in Washington for Duesberg and Farber. Science Guardian, 2010 (http://www.scienceguardian.com/blog/ whistleblower-awards-in-washington-for-duesberg-and-farber.htm).

10 Ross CA, Read J. Antipsychotic medications: myths and facts. In Models of Madness (eds J Read, LR Mosher, RP Bentall): 101-13. BrunnerRoutledge, 2004

11 Ellenberger H. Discovery of the Unconscious: The History and Evolution of Dynamic Psychiatry: 284-91. Basic Books, 1970.

12 Bentall RP. Preface: rational antipsychiatry. In Doctoring the Mind: Why Psychiatric Treatments Fail: xiv-xv. Allen Lane Publishers, 2009.

13 Smith RA. Drugs into bodies! A history of AIDS treatment activism. Body Positive 2006; 2 (http://www.thebody.com/content/ art31153.html).

14 Concorde Coordinating Committee. Concorde: MRC/ANRS randomised double-blind trial of immediate and deferred zidovudine in symptom free HIV infection. Lancet 1994; 343: 871-81.
15 Darbyshire JH. Delta: a randomised double-blind controlled trial comparing combinations of zidovudine plus didanosine or zalcitabine with zidovudine alone in HIV-infected individuals. Lancet 1996; 348: 283-91.

16 Rissmiller DJ, Rissmiller JH. Open forum: evolution of the antipsychiatry movement into mental health consumerism. Psychiatr Serv 2006; 57: 863-6.

17 Levy L. The National Schizophrenia Fellowship: a British self-help group. Soc Psychiatry 1981; 16: 129-35.

18 Young A. The DSM-III revolution. In The Harmony of Illusions: Inventing Post-Traumatic Stress Disorder: 89-116. Princeton University Press, 1995.

19 Eapen V, John G. Weight gain and metabolic syndrome among young patients on antipsychotic medication: what do we know and where do we go? Australas Psychiatry 2011; 19: 232-5.

20 McGorry PD, Yung A, Phillips L. Ethics and early intervention: keeping up the pace and staying in step. Schizophr Res 2001; 51: 17-29. 